\title{
OUTCOME OF NURSE-LED INTERVENTION ON KNOWLEDGE AND PRACTICE OF ASEPTIC TECHNIQUE AMONG SURGICAL NURSES IN TWO TEACHING HOSPITALS IN LAGOS STATE, NIGERIA
}

\author{
Adewunmi Mosunmola Christiana and Prof. R. A. Salawu
}

\author{
School of Nursing, Babcock University, Ilisan, Ogun State
}

\begin{abstract}
Cite this article:
Adewunmi M.C., R. A. Salawu (2021), Outcome of Nurse-Led Intervention on Knowledge and Practice of Aseptic Technique Among Surgical Nurses in Two Teaching Hospitals in Lagos State, Nigeria. African Journal of Health, Nursing and Midwifery 4(2), 88-104. DOI: 10.52589/AJHNMWCH721KJ.
\end{abstract}

\section{Manuscript History}

Received: 5 May 2021

Accepted: 20 May 2021

Published: 22 May 2021

Copyright $(9) 2020$ The Author(s). This is an Open Access article distributed under the terms of Creative Commons AttributionNonCommercial-NoDerivatives 4.0 International (CC BY-NC-ND 4.0), which permits anyone to share, use, reproduce and redistribute in any medium, provided the original author and source are credited.
ABSTRACT: Aseptic Technique (AT) plays a key role in the management of surgical cases within the hospital including the operating rooms. Surgical Nurse uses AT to alleviate the suffering of patients by protecting them during invasive clinical procedure thereby providing optimal care resulting in positive outcome. Therefore, the goal of this study was to train surgical nurses on knowledge and practice of aseptic technique in two teaching hospitals in Lagos State, Nigeria. A two group pre -test and post-test quasi experimental design was utilized and a sample size of 129 was used by simple random technique. A self-structured questionnaire was used for data collection, which was pilot tested and both were analysed through Cronbach Alpha and result yielded four research questions and six hypotheses were formulated. Data were analysed using SPSS version 22. Questionnaire was analysed using descriptive statistics of percentages, means and standard deviation while inferential statistics of $t$ test and Analysis of Variance(ANOVA) were used to test the hypotheses. Findings revealed that majority $28(42.5 \%)$ and $17(38.4 \%)$ of the participants were between the ages of 30 to 39 years in experimental and control group. The gender showed majority to be female $54(74 \%)$ and $33(82.5 \%)$ in both groups while most participants had degree in Nursing $(53.4 \%)$ and $(50 \%)$ in both groups. Their years of service showed that (34.2\%) and (45.0\%) have worked between 11 and 15 years, more than half were on grade level 7 and10. The preintervention mean scores of knowledge level was 27.009 (54.02\%) and 26.511 $(53.02 \%)$ in both groups, this revealed that the level of knowledge among them was below average. The pre-intervention mean scores level of practice in both groups was $7.432(53.09 \%)$ and 7.507 (53.62\%), this signified that the practice level of both group was below average. The post-intervention mean scores of the knowledge level in both groups was 43.807 (87.61\%) and 26.461 (52.92\%). The difference observed in the mean score of both groups was as a result of the training that only experimental group was exposed to, therefore, there was a significant improvement. The post-intervention mean scores of the practice level of both groups was 13.009 (92.92\%) and 7.616 (54.4\%). The difference observed in the mean score of both groups was as a result of the training of the experimental group therefore, there was a significant improvement. In conclusion, the influence of nurse-led intervention had a significant outcome on the training of knowledge and practice of aseptic technique that the experimental group was exposed to. It is therefore recommended that nurse clinicians be exposed to periodic training and re-training to facilitate good outcome of all invasive clinical procedures thereby reducing sepsis.

KEYWORD: Aseptic Technique, Intervention, Knowledge, Outcome and Practice 


\section{INTRODUCTION}

\section{Background to the Study}

The knowledge and practice of aseptic technique is germane to hospital settings be it privately or government owned especially in teaching hospitals where nurses are trained. In a study of asepsis by Taylor, (2020), the term asepsis has been defined as freedom from infection or infectious (pathogenic) material. Aseptic technique is a process designed to protect patients during invasive clinical procedures especially by nurses who stay with the patients round the clock, by using infection prevention and control measures to minimise, where possible the presence of pathogenic micro-organisms.

(National Health and Medical Research Council of Australia, 2019), stated that (AT) is achieved by identifying and protecting key sites (wounds or punctured sites) and key parts (equipment that come into contact with a key site) by consistently applying a set of principles. The dependent variable is nurses knowledge and practice while training program is the independent variable. It involves applying the strictest rules to minimize the risk of infection. Health Care Workers (HCW) use aseptic technique in surgery rooms, clinics, outpatient centres and other health care settings Stephens, (2017). It is also an important procedure in the prevention of Surgical Site Infections (SSIs) to alleviate patient suffering, also to help lower the cost of health care provision and prevent death

Surgery plays an increasingly prominent role in healthcare around the world and growing attention is being focused on the safety and quality of such care. Almost all surgical procedures (minor and major) are carried out in the operating room but recovery of the patient takes place in the surgical wards which could depend on the aseptic technique practiced (Fajemilehin, Oyediran, Faronbi and Ajibade, 2016). Despite the team work amongst doctors, nurses and hospital attendants, mishap still take place as a result of negligence and lack of adhering to proper standard of practice of aseptic technique by the introduction of micro -organisms into the wound thereby delaying the total recovery of the patient, which could cost the patient more financially by prolonging his/her stay in the hospital and can also result in death of the patient (Singhal, 2018).

It is estimated by World Health Organization (WHO), 2016), that 4.5 to 5.7 billion people are affected with Surgical Site Infection (SSI) per year due to lack of aseptic technique practices in hospital. $11 \%$ of clients who undergo surgery are infected in low and middle income countries.

In the United States of America (USA) and in some European countries it is stated by (Infection Control and Hospital Epidemiology, 2013), that the incidence of Surgical Site Infection is lesser, though it represents the second most type of Hospital Acquired Infection (HAI). In a study conducted by Nsekambabye (2017), citing Reichman et.al, (2009) it was reported that at a Boston surgical site infection accounts for $15 \%$ of all nosocomial infections and the most common nosocomial infection among surgical patients. This high rate of SSIs have also been reported by a study done by Sathyanarayana, Prashanth, Bhandare and Kavyashree (2011) among 1000 clients in India undergoing abdominal surgery where the researchers revealed that the rate of SSIs was $13.7 \%$.

WHO (2016), Labrague, Arteche, Begonia and Pacolor (2012) advised that adherence to the sterile technique principles by the sterile members (surgeon, assistant and scrub nurse) and the 
unsterile members (anesthetist, circulating nurse etc.), must be observed, as the practice of sterile technique prevent contamination of surgical wound. Preventing contamination of surgical site wound necessitates the efforts of all surgical team members to use their theoretical knowledge and experience in aseptic practices to provide their patients with optimal care resulting in positive surgical outcomes. The study done by Dhakal, Angadi and Lopchan, (2016) at selected Hospitals of Bharatpur in Nepal regarding the knowledge of aseptic technique among nurses', demonstrated that more than half of the participants (62\%) had high level of knowledge on aseptic technique, few (37.5\%) had average level of knowledge and none of the respondents had low knowledge on aseptic technique. The level of knowledge on aseptic technique was statistically significant $(\mathrm{p}=0.031)$ with age and educational qualification of the respondents but this research didn't assess the attitude of nurses towards aseptic technique.

In Africa, more than $20 \%$ of women who undergo caesarean section develop wound infection, affecting their health and the health of their babies. According to Thatcher and Hemavathy, (2015) aseptic technique is the basis of modern surgery and therefore strict adherence to the recommended practices of sterile technique is mandatory for the safety of the patient as well as for the personnel in the operating room complex.

\section{Statement of the Problem}

Despite training and licensing some nurses would not apply their knowledge and practice aseptic technique measures when carrying out procedures like hand washing, wearing of face mask, gloving, dressing of wound, preparation of trolleys, and removal of stiches to mention but few. The researcher observed that in some wards especially surgical where wounds are been cared for some nurses are the agents that spread surgical site infection by not washing their hands regularly, not changing their gloves after attending to each patient. Some nurses would not wear protective wears namely; masks, goggles, apron or surgical gloves for operated patient in case there is bleeding or to change drain site dressing while some will not prepare the patient's skin well enough before surgical intervention. There is poor control of traffic in the surgical units, while some health care givers do not take aseptic technique practices as core avoidable morbidity Fajemilehin, Oyediran, Faronbi and Ajibade (2016).

The researcher being a perioperative nurse noted this because there was about $10 \%$ of surgical cases wound breaking down. Wound infections are the second most commonly encountered type of nosocomial infection in the developing countries Fajemilehin, Oyediran, Faronbi and Ajibade (2016). Knowing the fact that wound infection may be induced, by not practicing appropriate aseptic techniques on the wards, it is essential to implement aseptic technique principles in the surgical units because it is of prime importance in the wound healing process. Surgical Site Infections (SSIs) are the leading cause of Health Associated Infections (HAIs) particularly in developing countries, centre for disease control (CDC, 2016); the incidence varies from hospital to hospital just as it equally varies from country to country. Available statistics show that incidence is lower in the developed countries with incidence of 2.0 to $6.4 \%$ compared to developing countries where incidence has been estimated at between 5.5 and $25 \%$ (Kolade, 2017).

Thus, this study intends to examine the outcome of a nurse-led intervention on knowledge and practice of aseptic technique among surgical nurses in two teaching hospitals: Lagos University 
Teaching Hospital, Idi-araba and Lagos State University Teaching Hospital, Ikeja in Lagos State, Nigeria

\section{Objective of the Study}

The main objective of the study is to assess the outcome of nurse-led intervention on the knowledge and practice of aseptic techniques among surgical nurses in two teaching hospitals in Lagos State, Nigeria. The specific objectives are to:

1. assess the pre intervention knowledge of surgical nurses in experimental and control groups on aseptic technique;

2. assess the pre intervention practice of aseptic techniques among surgical nurses in experimental and control groups;

3. present an intervention training package;

4. compare pre intervention knowledge of aseptic technique among surgical nurses between experimental and control groups;

5. compare post intervention knowledge of aseptic technique among surgical nurses between experimental and control groups;

6. compare pre intervention practice of aseptic technique among surgical nurses between experimental and control groups and

7. compare post intervention practice of aseptic technique among surgical nurses between experimental and control groups.

\section{Research Questions}

This study would seek to answer to the following questions:

1. what is the level of the knowledge on aseptic techniques among surgical nurses pre and post nurse-led intervention?

2. what is the level of practice of aseptic technique among surgical nurses pre and post nurseled intervention?

3. what is the significant difference between demographic characteristics and knowledge and practice towards aseptic techniques?

4. what is the level of practice of aseptic technique among surgical nurses post nurse-led intervention

\section{Research Methods}

The study was done using quantitative descriptive design by two groups pre-test and post-test quasi experimental method. The two groups were used because the population size was large. This study investigated a nurse-led intervention on aseptic technique. The research was conducted in two teaching hospitals in Lagos State namely, Lagos State University Teaching 
Hospital, Ikeja (LASUTH). The study utilized 108 nurses from LASUTH and 85 from LUTH working in surgical, emergency, obstetrics and gynaecological units of the captured teaching hospital. A self-structured questionnaire with 60 questions comprising three sections. Section A containing 9 sets of demographic questions. Section B with 51 questions on knowledge of Aseptic Technique and section C with 14 items needed to practice Aseptic Technique.

The instruments used for data collection include:

i. Surgical Nurses Demographic sets of Questionnaire (SNDQ), which consists of nine questions.

ii. Test Paper on Knowledge of Aseptic Technique. (TP-KAT)

The instrument was used to measure the cognitive domain in other to determine their knowledge in aseptic technique. It consists of a total number of 51 questions.

Section A: Contains questions on Socio-demographic data and it comprises 9 questions.

Section B: Contains questions on Nurses knowledge of aseptic technique and it comprises 51 questions. The maximum score for correct response for knowledge of aseptic technique was 62 points. The scores were categorised into three: Scores between 1 and 16 was considered as below average, scores between 17 and 32 was considered as average while scores between 33 and 50 was considered as above average.

\section{Presentation of data: Tables}

The Tables showed different results obtained through the analysis of the questionnaire that was administered.

Table 4.1: Participants' Demographic Data $(\mathrm{N}=113)$

\begin{tabular}{|c|c|c|c|c|c|}
\hline \multirow{2}{*}{\multicolumn{2}{|c|}{ Variable }} & \multicolumn{2}{|c|}{ Experimental $(\mathrm{N}=73)$} & \multicolumn{2}{|c|}{ Control $(\mathrm{N}=40)$} \\
\hline & & Frequency & $\begin{array}{c}\text { Percent } \\
(\%)\end{array}$ & Frequency & $\begin{array}{c}\text { Percent } \\
(\%)\end{array}$ \\
\hline \multirow[t]{7}{*}{ Age } & $>$ 20years & - & - & - & - \\
\hline & 21-29yrs & 17 & 23.3 & 10 & 25.0 \\
\hline & 30-39yrs & 28 & 38.4 & 17 & 42.5 \\
\hline & $40-49 y r s$ & 17 & 23.2 & 8 & 20.0 \\
\hline & 50yrs above & 11 & 15.1 & 5 & 12.5 \\
\hline & Total & 73 & 100.0 & 40 & 100.0 \\
\hline & & \multicolumn{2}{|c|}{$\begin{array}{c}\text { Mean age }=37.8 \\
\mathrm{SD}=5.67\end{array}$} & \multicolumn{2}{|c|}{$\begin{array}{c}\text { Mean age }=36.6 \\
\mathrm{SD}=6.01\end{array}$} \\
\hline \multirow[t]{3}{*}{ Gender } & Male & 19 & 26.0 & 7 & 17.5 \\
\hline & Female & 54 & 74.0 & 33 & 82.5 \\
\hline & Total & 73 & 100.0 & 40 & 100.0 \\
\hline \multirow[t]{3}{*}{ Marital Status } & Single & 21 & 28.8 & 13 & 32.5 \\
\hline & Married & 42 & 57.5 & 22 & 55.0 \\
\hline & Divorced/separated & 10 & 13.7 & 5 & 12.5 \\
\hline
\end{tabular}




\begin{tabular}{|c|c|c|c|c|c|}
\hline & Total & 73 & 100.0 & 59 & 100.0 \\
\hline \multirow[t]{5}{*}{ Qualification } & Certificate & 3 & 4.1 & - & - \\
\hline & Diploma & 24 & 32.9 & 14 & 35.0 \\
\hline & Degree & 39 & 53.4 & 20 & 50.0 \\
\hline & Post Graduate & 7 & 9.6 & 6 & 15.0 \\
\hline & Total & 73 & 100.0 & 59 & 100.0 \\
\hline \multirow{6}{*}{$\begin{array}{ll}\text { Years } & \text { of } \\
\text { service } & \end{array}$} & $0-5$ & 7 & 9.6 & 5 & 12.5 \\
\hline & $6-10$ & 17 & 23.3 & 5 & 12.5 \\
\hline & $11-15$ & 25 & 34.2 & 18 & 45.0 \\
\hline & $16-20$ & 10 & 13.7 & 8 & 20.0 \\
\hline & 21years and above & 14 & 19.2 & 4 & 10.0 \\
\hline & Total & 73 & 100.0 & 59 & 100.0 \\
\hline \multirow[t]{3}{*}{ Grade level } & $7-10$ & 43 & 58.9 & 26 & 65.0 \\
\hline & $12-14$ & 30 & 41.1 & 14 & 35.0 \\
\hline & Total & 73 & 100.0 & 40 & 100.0 \\
\hline \multirow{3}{*}{$\begin{array}{l}\text { heard of } \\
\text { aseptic tech. }\end{array}$} & Yes & 73 & 100.0 & 40 & 100.0 \\
\hline & $\mathrm{No}$ & - & - & - & - \\
\hline & Total & 73 & 100.0 & 40 & 100.0 \\
\hline
\end{tabular}

The findings from Table 4.1 revealed that majority $28(38.4 \%)$ and $17(42.5 \%)$ of the participants that participated in the study were between the ages of 30 to 39 years in control and experimental group respectively. The gender showed majority to be female in both experimental $(54 ; 74 \%)$ and control $(33 ; 82.5 \%)$ group. The marital status of the participants shows that $42(57.5 \%)$ in the experimental group and $22(55 \%)$ in the control group were married, and majority had degree in Nursing in both the experimental (53.4\%) and control (50\%) groups. Their years of service shows that most of them in the experimental group (34.2\%) and control group (45.0\%) have worked between 11 and 15 years, more than half of the participants in both groups were on grade level 7 and 10.

\subsection{Answering of Research Questions}

Research Question 1: What is the level of the knowledge among surgical nurses in pre intervention between experimental and control group on aseptic technique?

Table 4.2: Pre-intervention knowledge mean score of participants on aseptic techniques in the experimental and control groups

\begin{tabular}{|c|c|c|c|c|c|}
\hline \multirow{3}{*}{$\begin{array}{l}\text { knowledge on } \\
\text { aseptic techniques }\end{array}$} & \multirow{3}{*}{$\begin{array}{l}\text { Category } \\
\text { of scores }\end{array}$} & \multicolumn{4}{|c|}{ Pre- intervention } \\
\hline & & \multicolumn{2}{|c|}{ Experimental } & \multicolumn{2}{|c|}{ Control } \\
\hline & & Freq. & $\begin{array}{c}\text { Percent } \\
(\%)\end{array}$ & Freq. & $\begin{array}{c}\text { Percent } \\
(\%)\end{array}$ \\
\hline Below average & $1-16$ & 9 & 12.3 & 8 & 20.0 \\
\hline Average & $17-32$ & 55 & 75.4 & 27 & 67.5 \\
\hline Above average & $33-50$ & 9 & 12.3 & 5 & 12.5 \\
\hline Total & & 73 & 100.0 & 40 & 100.0 \\
\hline
\end{tabular}


Research Question 2: What is the pre intervention level of practice of aseptic technique among surgical nurses in experimental and control group?

Table 4.3: Pre-intervention practice mean score of participants on aseptic techniques in the experimental and control groups

\begin{tabular}{|l|c|c|c|c|c|}
\hline Practice on aseptic & \multirow{2}{*}{$\begin{array}{c}\text { Category } \\
\text { techniques }\end{array}$} & \multicolumn{4}{|c|}{ Pre- intervention } \\
\cline { 3 - 6 } & & \multicolumn{2}{|c|}{ Experimental } & \multicolumn{2}{|c|}{ Control } \\
\cline { 3 - 6 } & & Freq. & $\begin{array}{c}\text { Percent } \\
(\boldsymbol{\%})\end{array}$ & Freq. & $\begin{array}{c}\text { Percent } \\
(\boldsymbol{\%})\end{array}$ \\
\hline Below average & $1-5$ & 31 & 42.5 & 15 & 37.5 \\
\hline Average & $6-10$ & 32 & 43.8 & 20 & 50.0 \\
\hline Above average & $11-15$ & 10 & 13.7 & 5 & 12.5 \\
\hline
\end{tabular}

Table 4.2 presents the level of the knowledge among surgical nurses in pre intervention between experimental and control group on aseptic technique. The pre-intervention mean scores of the knowledge level of the participants on aseptic technique in the experimental group was $27.009(54.02 \%)$ and $26.511(53.02 \%)$ in the control group, it could be said that the level of the knowledge among surgical nurses in pre intervention between experimental and control group on aseptic technique was not good enough.

Research Question 3: What is the level of the knowledge among surgical nurses in post intervention between experimental and control group on aseptic technique?

Table 4.4: Post-intervention knowledge mean score of participants on aseptic techniques in the experimental and control groups

\begin{tabular}{|l|c|c|c|c|c|}
\hline \multirow{2}{*}{$\begin{array}{l}\text { knowledge on } \\
\text { aseptic techniques }\end{array}$} & \multirow{2}{*}{$\begin{array}{c}\text { Category } \\
\text { of scores }\end{array}$} & \multicolumn{5}{|c|}{ Pre- intervention } \\
\cline { 3 - 6 } & & Experimental & \multicolumn{2}{c|}{ Control } \\
\cline { 3 - 6 } & & & $\begin{array}{c}\text { Percent } \\
(\%)\end{array}$ & Freq. & $\begin{array}{c}\text { Percent } \\
(\%)\end{array}$ \\
\hline Below average & $1-16$ & - & - & 5 & 12.5 \\
\hline Average & $17-32$ & 24 & 32.9 & 30 & 75.0 \\
\hline Above average & $33-50$ & 49 & 67.1 & 5 & 12.5 \\
\hline Total & & 73 & 100.0 & 40 & 100.0 \\
\hline Mean & & \multicolumn{2}{|c|}{43.807} & \multicolumn{2}{c|}{26.461} \\
\hline Percentage (\%) & & \multicolumn{2}{|c|}{87.61} & \multicolumn{2}{c|}{52.92} \\
\hline Standard dev. & & \multicolumn{2}{|c|}{5.990} & \multicolumn{2}{c}{7.651} \\
\hline
\end{tabular}

Table 4.4 presents the post-intervention level of the knowledge among surgical nurses between experimental and control group on aseptic technique. The post-intervention mean scores of the knowledge level of the participants on aseptic technique in the experimental group was 43.807 $(87.61 \%)$ and $26.461(52.92 \%)$ in the control group. The difference observed in the mean score of participants in the experimental and control groups could be as a result of the intervention given to the experimental group. Therefore, an improvement was observed in the experimental group compared to the control group. 
Research Question 4: What is the level of practice of aseptic technique among surgical nurses post nurse-led intervention?

Table 4.5: Post-intervention practice mean score of participants on aseptic techniques in the experimental and control groups

\begin{tabular}{|c|c|c|c|c|c|}
\hline \multirow{3}{*}{$\begin{array}{l}\text { Practice on aseptic } \\
\text { techniques }\end{array}$} & \multirow{3}{*}{$\begin{array}{l}\text { Category } \\
\text { of scores }\end{array}$} & \multicolumn{4}{|c|}{ Post- intervention } \\
\hline & & \multicolumn{2}{|c|}{ Experimental } & \multicolumn{2}{|c|}{ Control } \\
\hline & & Freq. & $\begin{array}{c}\text { Percent } \\
(\%)\end{array}$ & Freq. & $\begin{array}{c}\text { Percent } \\
(\%)\end{array}$ \\
\hline Below average & $1-5$ & - & - & 13 & 32.5 \\
\hline Average & $6-10$ & 16 & 21.9 & 20 & 50.0 \\
\hline Above average & $11-15$ & 57 & 78.1 & 7 & 17.7 \\
\hline Total & & 73 & 100.0 & 40 & 100.0 \\
\hline Mean & & \multicolumn{2}{|c|}{13.009} & \multicolumn{2}{|c|}{7.616} \\
\hline Percentage (\%) & & \multicolumn{2}{|c|}{92.92} & \multicolumn{2}{|c|}{54.4} \\
\hline Standard dev. & & \multicolumn{2}{|c|}{1.876} & \multicolumn{2}{|c|}{1.428} \\
\hline
\end{tabular}

Table 4.5 presents the post-intervention level of practice of aseptic technique among surgical nurses post nurse-led intervention. The post-intervention mean scores of the practice level of the participants on aseptic technique in the experimental group was 13.009 (92.92\%) and 7.616 $(54.4 \%)$ in the control group. The difference observed in the mean score of participants in the experimental and control groups could be as a result of the intervention given to the experimental group. Therefore, an improvement was observed in the experimental group compared to the control group.

\section{DISCUSSIONS OF FINDINGS}

\section{Discussion of Research Questions}

Pre intervention knowledge between experimental and control groups on aseptic technique

The level of the knowledge among surgical nurses in pre intervention between experimental and control group on aseptic technique was not good enough. Though majority of the respondents demonstrated moderate knowledge. This study is similar to a study conducted by Kolade, Salisu, Sanusi, Hanson and Adelani (2017), which showed that respondents demonstrated relatively high level of knowledge on surgical site Infections (SSIs) prevention. Also, this finding corroborate that of Singh, Rani and Kumari (2016) on the assessment of knowledge of staff nurses regarding aseptic techniques at selected hospital in which the results showed that the maximum staff nurses, that is $43(63.24 \%)$ were having average knowledge while of $25(36.76 \%)$ were having poor average knowledge, knowledge regarding aseptic techniques. 


\section{Pre intervention practice of aseptic technique between experimental and control groups?}

The pre-intervention mean scores of the level of practice of aseptic technique among surgical nurses in experimental and control group was not good enough. This showed that nurses practice aseptic techniques but the practice may not be regularly done or was done haphazardly in the two groups. This was equally confirmed during the intervention period. This study therefore was in line with that of Abubakar et al., (2017) which determined the attitude and practices of nurses in Ogun State selected hospitals towards aseptic techniques in prevention of cross infection. Their findings that all the respondents (100\%) practiced aseptic techniques, however, there was variation in the practice as $70.5 \%$ of respondents opined to have practiced aseptic techniques sometimes, $22.1 \%$ practice it regularly. Furthermore, $82.1 \%$ of the respondents used both methylated spirit as an agent for sterilization and boiling technique for sterilization.

\section{Post-intervention knowledge mean score of participants on aseptic techniques in the experimental and control groups}

The post-intervention mean scores of the knowledge level of the participants on aseptic technique in the experimental group was better than the control group. The difference observed in the mean score of participants in the experimental and control groups could be as a result of the intervention given to the experimental group. Therefore, an improvement observed in the experimental group compared to the control group was due to the training given. This finding was consistent with the findings of Hang and Jang (2016), in the study on the effect of hand washing education programme on knowledge, attitude and performance of aseptic technique among pre-practicum nurses. They found that the experimental group showed significant increase in the attitude and performance of aseptic technique after the intervention. It was concluded that the aseptic technique education programme had significant impact on attitude and performance of aseptic technique to the participants.

\section{Post-intervention practice mean score of participants on aseptic techniques in the experimental and control groups}

The difference observed in the mean score of participants in the experimental and control groups could be as a result of the intervention given to the experimental group. Therefore, an improvement was observed in the experimental group compared to the control group. The result was similar to a study which assessed the effect of training on hospital waste management by Sushma (2014), in Bangalore, among the staff of Dental Teaching Hospital. It was found that the training programme increased the knowledge as well as the sense of responsibility resulting in change of attitude and practice towards hospital waste management which is a means of controlling infection. Also, this finding supported previous study by Razaee et al., (2014), in a study conducted among medical students at Shiraz University of Medical Science on Knowledge Attitude and Compliance with Hand Hygiene. The result showed that the training programme improved knowledge, attitude and performance of medical students in infection control practices of hand hygiene in short and long time period. 


\section{SUMMARY}

Aseptic technique is the most acceptable method of practice to prevent infections in the surgical units of any health institution. Also, hospital acquired infection can be averted through this means when (AT) is holistically practiced therefore, patient's stay in the hospital is not prolonged. The best clinical care in the world can be worthless if patients pick up other infections while they are in the hospital. The surgical nurses can prevent the nosocomial infections by consciously applying aseptic technique when attending to patients. The effects of aseptic technique training program on surgical nurses' knowledge and practice to promote infection control was the focus of this study. A total number of 142 participants started the study from the two teaching hospitals.

Simple random sampling technique was used to select the experimental group which was LASUTH, while the control group was LUTH. Proportionate stratified random sampling technique was then used to select the participants for this study. 73 surgical nurses were used for the selection of the experimental group, that is, LASUTH while 40 surgical nurses were used for the selection of control group, that is, LUTH. A total of 113 participants completed the study The training has increased the knowledge and practice of participants on aseptic techniques. This study also achieved significant mean difference in knowledge and practice of aseptic technique. Succinctly the training programme has empowered the surgical nurses to acquire more knowledge and practice of aseptic technique and to become infection control link nurses for their teaching hospitals. However, there is still need for surgical nurses to be more educated on sterile technique principles to ensure safety of the operated clients and to reduce the rate of post-operative wound infection among them.

\section{RECOMMENDATIONS}

Based on the findings of this study, the following recommendations were made:

\section{For nurse educators to have}

i. An annual education and training update in aseptic technique including practical assessment and demonstrate competency.

ii. Greater understanding of aseptic technique and to be able to clearly articulate the principles of aseptic technique to students and demonstrate how these might be applied to practice.

\section{For nurse clinicians}

i. A quarterly education and training update in aseptic technique including assessment of the application of aseptic technique that is relevant to the practitioners' area of clinical practice.

ii. Education and training updates which refresh knowledge and understanding of the hierarchy of de-contamination and fundamental principles of asepsis. 


\section{For infection prevention nurses to:}

i. Receive an annual education and training update in aseptic technique including practical assessment.

ii. Collaborate closely with facilitators to develop curriculum at Mandatory Continuing Professional Development Program (MCPDP) for nurses training on aseptic technique, in order to function as one 'community of practice' and other core skills. Educators and infection prevention teams should agree upon what is taught and assessed about aseptic technique in pre-registration programs and in educational updates for qualified nurses.

iii. Work together with educators at national, state and local level to develop a policy for aseptic technique. General policy should provide clear guidance upon the standard of practice expected, roles and responsibilities for education, training and audit of aseptic technique.

The following suggestions are made based on the findings of the study.

1. Similar study should be conducted on other categories of health workers like doctors, laboratory scientists, pharmacists and so on in the two hospitals.

2. Future research using observation technique should be done among student nurses to assess their practice of sterile technique in hospital clinical areas.

3. A replication of this study is recommended in other settings to promote the generalizability of the findings.

4. Other studies should explore the effectiveness of different approaches to teaching and assessment of aseptic technique. This might include exploring innovative technologies for providing immediate feedback upon students' performance of aseptic technique.

\section{REFERENCES}

Aaron, D. (2015). Aseptic technique Surgery Encyclopaedia. 7, 12-20. Retrieved from www.surgeryencylcopeadia.com./A-Ce/Aseptic-Technique.htlmiii

Abraham Sonia P, Rachael Deva, Babu Valliammal (2016); The knowledge and practice of operating room nurses regarding sterile technique in a tertiary hospital, South India. Journal of Nursing and Health Science, 5 (3),2320-1940.

Abubakar, I.A, Olubiyi, S.K, Edna, T, Umar, N.J., Rejuaro, F.M., Ibraheem, M.A (2017). Attitude and Practices of Nurses at Ogun State hospitals towards aseptic techniques in prevention of cross infection. Ilorin Journal of Health Promotion and Environmental Health Education.

Al-Rawajfah, O.M., Hweidi, I, Alkhalaileh, M., Khader, Y.S., Shboul, S. (2013); Compliance of Jordanian registered nurses with infection control guidelines: a national population study. DOI; 10.1186/2047-2994-2-S1-027. Antimicrobial Resistance \& Infection Control 2(1)

ANTT - Theoretical Framework for Clinical Practice. Version 25 2011. The Association of Safe Aseptic Practice (ASAP) www.antt.org.uk

Bizimanal, J. K., Ndoli, J., Bayingana, C., Baluhe, I., Gilson, G.J., and Habimana, E (2016); Prevalence and Risk Factors for Post Caesarean Delivery Surgical Site Infection in a 
Teaching Hospital Setting in Rural Rwanda: A Prospective Cross-Sectional Study. Inc.J Curr.Microbiol. App.Sci 5(6): 631-641.

Blaser MJ, eds. Mandell, Douglas, and Bennett's Principles and Practice of Infectious

Diseases 9th ed. Philadelphia, PA: Elsevier; 2020: chap 298.

Bloom's Taxonomy, Effective Learning Objectives. Wessex Event (2015) www.slideshare.net

Bloom's Taxonomy, Learning Outcomes to Bloom's Level and Taxonomy www.uark.edu (2015)

Brisibe, S., Ordinioha, B., Gbeneolol, P.K., Knowledge, Attitude, and Infection Control Practices of two tertiary hospitals in Port Harcourt, Nigeria. Niger J Clin Pract 2014; 17:691-5.

Burns N., and Grove SK., (2007). Understanding Nursing Research: Building an Evidence Based Practice 4th Ed. Saunders http://www.raosoft.com/samplesize.html.

Centers for Disease Control and Prevention. The National Institute for Occupational Safety and Health (NIOSH) website. Personal protective equipment.

http://www..cdc,gov/niosh/ppe. Updated January 31, 2018. Accessed January 11, 2020.

Colopinto K. (2010). Comparison of the Cultural values of Sweden to Patient Safety culture Association of Operating Room Nurses Journal,92(2), 224-227.

Dai Chien-Yun, Chen Wan-Fei, Yuan Yu-Hsi, Yen Chia-Hung (2012). A Study on Modification of Knowledge, Attitude and Practice on Vocational High School Electronics Courses Integrated with Nanotechnology Concept. Int. J. of Thermal \& Environmental Engineering Volume 4, No. 1 (2012) 73-79

Department of Health (2007) Saving lives: reducing infection, delivering clean and safe care: High impact intervention No 4 - care bundle to prevent surgical site infection.DoH, London. Available online at:www.clean-safe-care.nhs.uk/cms/ toolfiles/22/SL_HII4_v2.pdf

Devi Barkha and Reshma Tamang. (2014). Knowledge on Practice of Aseptic Technique During Delivery Among Health Professionals in Selected Government hospitals of Sikkim. SMU Medical Journal, Volume - 1, No. 2.

Dhakal, B., Angadi, S. \&Lochan, M., 2016. Nurses' Knowledge and Practice of Aseptic Technique in the Operation Theatre at selected Hospitals of Bharatpur. 2(2), pp.32-34.

Dlamini, L.J, 2014. Nursing \& Care Operating Room Nurses' Knowledge and Practice of Sterile Technique. 1(4), pp.1-5

Dolan, S.A.; Felizardo, G.; Barnes, S.; Cox, T.R.; Patrick, M.; et al.: "APIC position paper: safe injection, infusion, and medication vial practices in care." American journal of infection control, 38.3, (2010), PP : 167172.

Eckman K, Walker R (2008). Knowledge, Attitudes and Practice (KAP) Survey-summary report for the Duluth Lakeside stormwater reduction project (LSRP). Duluth: Water Resources Center, University of Minnesota.

EtikanIlker, Musa Sulaiman Abubakar, Rukayya Sunusi Alkassim (2016). Comparison of Convenience Sampling and Purposive Sampling. American Journal of Theoretical and Applied Statistics doi: 10.11648/j.ajtas.20160501.11 ISSN: 2326-8999 (Print); ISSN: 23269006 (Online)

Fajemilehin, B., Oyediran, O., Faronbi J., and Ajibade, P., (2016). Safety implementation of a checklist based Surgical Safety intervention. BMJ Quality \& Safety, 20(1), 102-107.

Faukner, G. (2013). Aseptic technique. South Australia health. 1/5-18 Retrieved from http://www.sahealth.sa.gov.au/wps/wcn/connect/public+content/sa

Graf K, Otte E, Vonberg R-P, Kuhn C, Schilling T, Haverich A \&Chabermy, IF. Surgical site 
infections - economic consequences for the health care system. Langenbecks Arch Surg (2011), 396:453-459

Hubbard, S. M., \& Hayashi, S. W. (2013). Use of diffusion of innovations theory to drive a federal agency's program evaluation. Evaluation and Program Planning, 26, 49-56. doi:10.1016/S0149-7189(02)00087-3

Humphreys H, \&Cunney, R. (2008). Performance Indicators and the Public Reporting of Healthcare-Associated Infection Rates.Clin.Microbiol. Infect. 14(10):892-894.

Infection Control and Hospital Epidemiology. (2013). Journal of Chicago, 34(4). Retrieved from http://www.jstor.org/discover/10.1086/669857? uid $=2 \&$ uid $=4 \&$ sid $=2110$ 3002720747

Jainandunsing L. (2011). Knowledge and compliance with standard precaution among nurses. College of nursing, state University Philippines. International journal of advanced nursing studies, science publishing corporation. vol 1(2) (2012) 84 -94.

Jennifer, S. (2012). Applying aseptic technique in all clinical settings. Infection control today, 5/3-20 retrieved from http://www.infectioncontroltoday.com/article/2006/06/applying_ aseptic-technique-in-all-clinical-settin.aspx.

Kilpatrick W (2002). Infection control measure advanced Nursing studies. College of nursing; Samar State University Philippines, Science publishing corporation. International Journal of Infection control. Vol 1 84-94

Kingsley, A. (2008). Aseptic techniques. Wound Essentials, 3(1), 134-141.

Kingsley, A. (2008). Aseptic techniques. Wound Essentials, 3(1), 134-141.

Kolade OA, Abubakar S, Sanusi R. A, Hanson V F, Adelani T (2017). Knowledge, Attitude and Practice of Surgical Site Infection Prevention among post-operative nurses in a tertiary health institution in North-Central Nigeria. Vol. 9(6), pp. 65-6.

Labrague, LJ., Arteche, DL., Begonia, CY., Pacolor, NF., (2012) Operating Room Nurses Knowledge and Practice of Sterile Techniques. J Nurs Care 1:113.

Lippincott Williams \& Wilkins, Baltimore, MD 1989-2001 Hand washing procedure.

Lothian, S. F., Ferrence, R., \&Kaiserman, M. J. (1996).Restrictions on smoking. In T. Stephens, Morin, M. (eds.), Youth Smoking Survey, Technical Report, Ottawa: Minister of Supply and Services Canada.

Mahmud N, Abdul Sahib S (2011). Assessment of Nurses' Practices toward Infection Control Standardized Precautions in Azady Teaching Hospital in the City of Kirkuk. Iraqi Natl. J. Nurse. Specialties 24(1):52-58.

McRobert J, Stiles K (2014). Ten Top Tips. The management of burns wounds. Wound International 5(1):9-14

Navjyot Singh, Manisha Rani, Priyanka Kumari (2016). Assessment of Knowledge of Staff Nurses Regarding Aseptic Technique Retrieved from http://www.researchgate.net

Nsekambabaye Jean Pierre (2017). Operating room nurse's knowledge, attitude and practice of sterile techniques in Rwanda referral hospitals. (M.Sc. Thesis).

O'Grady, N.P.; Alexander, M.; Burns, L.A.; Dellinger, E.P.; Garland, J.; et al.: "Guidelines for the prevention of intravascular catheter-related infections." Clinical infectious diseases, 52.9, (2011), PP: 162-193.

Palmore TN. Infection prevention and control in the health care setting. In: Bennett JE, Dolin $\mathrm{R}$,

Pankaj, P., Phillip, L. \& Wilson, S. (2014). Aseptic techniques true/false questions. Proprofs 8/28-36. Retrieved from www.proprofs.com/quizschool/story.php?title=aeptictechnique-truefalse 
Peterhams, W.W. (2014). Aseptic non-touch technique. Nursing times 15/1-16 Retrieved fromhttp://www.gosh.nhs.uk/health-professionals/clinical-guidelines/aseptic-techniquetheatre

Petersen C, editor: Perioperative nursing data set, ed 3, Denver, 2011, Association of perioperative Registered Nurses, Inc., The Association.

Philip H (2007). Double gloving to reduce surgical cross-infection. Cochrane Database Syst Rev. 3: Cd0030

Rajinder K, Indarjit Walia, Baljit Kaur. (2008). Knowledge, Attitude and Practice regarding Universal Precautions among nursing personnel. Nursing and Midwifery Research Journal, Vol-4, No. 1, 16-33.

Rav-Marathe Karen, Wan Thomas and Marathe Sam (2016). A Systematic review on the KAP-O Framework for Diabetes Education and Research. Medical Research Archives, Vol. 4, issue 1

Rothrock, J. C., \&McEwen, D. R. (2019). Alexander's care of patient in surgery (13th ed.). Missouri: Mosby

Sathyanarayana, V., Prashanth, H. V., Bhandare. B., \& Kavyashree, A. N. (2011). Study of surgical site infections in abdominal surgeries. Journal of Clinical and Diagnostic Research, 5, 935 -939. Retrieved from www.jcdr.net/article fulltext.asp

Singhal Hemant (2018). Wound infection treatment and management. Available at www.emedicine.medscape.com/article/188988-treatment.Accessed 3rd November 2019.

Sokolove PE, Moulin A. Standard precautions and infectious exposure management. In: Roberts JR, Custalow CB, Thomsen TW, eds. Roberts and Hedges' Clinical Procedures in Emergency Medicine and Acute Care. 7th ed. Philadelphia, PA: Elsevier; 2019: chap 68.

Stephens C, (2017). What is Aseptic Technique. www.healthline.com

Tade, A. T., Ngwayu, C. L. \& Samuel, N. C (2019). Assessment of Knowledge of Staff Nurses Regarding Aseptic Techniques at Selected Hospitals. Navjyot Singh, Priyanka Kumari

Taylor, S; (2020). Principles of Asepsis 1: the rationale for using technique. www.nursingtimes.net

Thatcher WP, Hemavathy Rosenthal R (2015). Economic burden of surgical site infections at a European university hospital. Infect Control Hosp Epidemiol. 29(7):623-25

Ude-Akpeh, Chinelo Edith and Ezeoke, Chinwe B (2017). Knowledge, Attitude and Practice (KAP) Study of Diffusion of Flood Alert Campaign in Anambra State. Volume 6 Issue 6.

US Food and Drug Administration website. Medical gloves. http://www.fda.gov/medicaldevices/personal/personal-protective-equipment-infection-control/medical-gloves. Updated March 20, 2020. Accessed June 5, 2020.

Wang, P. W., Huang, J. J., Tang, H. L., Yeh, G. L. \& Tseng, C. C. (2009). A Case Study on Knowledge, Attitude, and Behavioural Intention Related to Green Consumption and Related Factors for 7(superscript) 9(superscript) Students on One School in Taipei City. Chinese Journal of Science Education, 17(3), 255-274.

Wick EC, Gibbs L, Indorf LA, Varma MG, Garcia-Aguilar J (2008). Implementation of Quality Measures to Reduce Surgical Site Infection in Colorectal Patients. Dis. Colon Rectum 51:1004-1009. 
Wistrand Camilla, Bo Söderquist, Karin Falk-Brynhildsen and Ulrica Nilsson. (2018).

Exploring bacterial growth and recolonization after preoperative hand disinfection and surgery between operating room nurses and non-health care workers: a pilot study. Wistrand et.al, BMC Infectious Diseases.18:466.

World Health Organisation (2016). Surgical Site Infection Prevention Guideline.http://www.who.int/gpsc/ssi-prevention-guidelines/en/

World Health Organisation (2020). Patient Safety, save lives, Clean Your Hands.

Xie, H. (2013). AORN's recommended practices for sterile technique. Restoring sight 4/1020 Retrieved from http://www.restoresight.org/wpcontent/uploads/2012/11/AORNproposed-changes-sept-2012.pd 